\section{KAUST-MRS paves the way for international chapters}

\author{
mrschapter.kaust.edu.sa
}

$\mathrm{S}^{\mathrm{e}}$ ven years ago, Professor Husam Alshareef, a faculty member in materials science and engineering at King Abdullah University of Science and Technology (KAUST) in Saudi Arabia, initiated an effort to establish the first international Materials Research Society (MRS) Student Chapter outside of the United States.

The KAUST-MRS Student Chapter had to prove that international MRS chapters can succeed. The chapter's faculty and student pioneers had a vision in mind - to promote materials science and engineering in Saudi Arabia and across the Middle East, and to create a bridge between KAUST and materials professionals worldwide through MRS. The chapter quickly increased its membership and fostered a dynamic that encouraged learning for its members, faculty, and industry partners interested in materials research from across the region. The chapter simultaneously remained engaged with MRS, showcasing itself as an example of international engagement

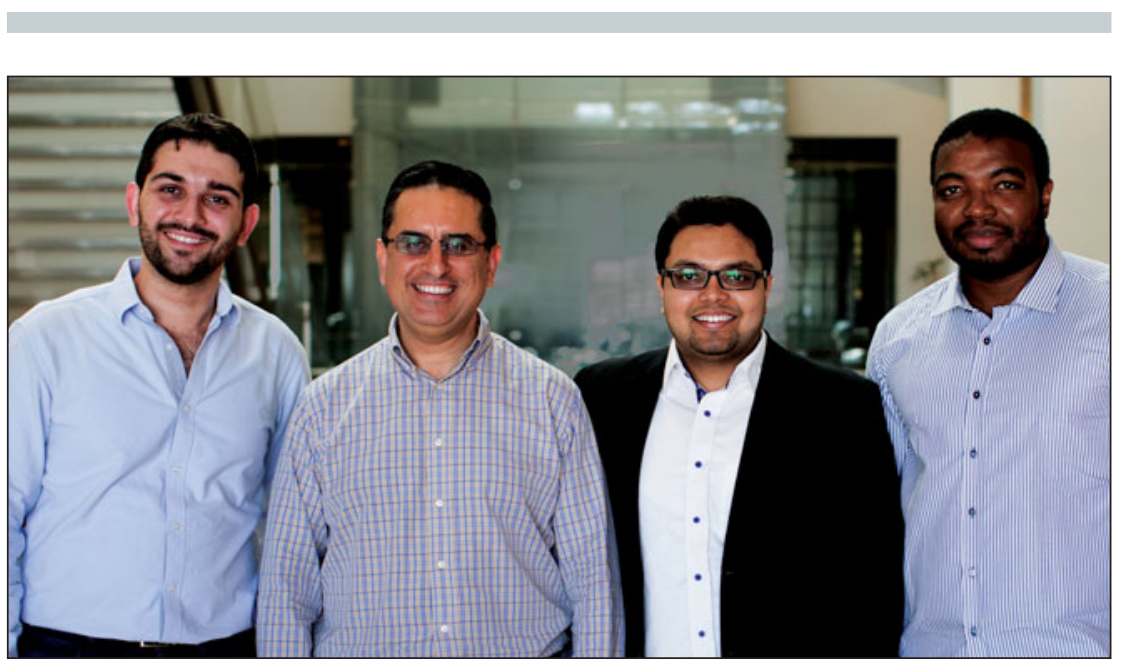

(From left to right): Student Ahmed Mansour, Professor Husam Alshareef, and students Rahim Munir and Guy Olivier Ngongang Ndjawa set up the student-organized events, a series of seminars and workshops on publishing and writing skills, at the 2016 MRS Fall Meeting \& Exhibit in Boston, Mass., as part of their work with the KAUST-MRS Student Chapter. Photo by Nicholas Demille, KAUST News. that MRS leadership seeks to establish worldwide.

Since its creation, the chapter has been busy with a wide variety of events Seminars with topics ranging from the publication process of scientific papers to materials-related talks by leading international researchers have taken place on the KAUST campus. A materials characterization seminar series was also initiated and has since covered characterization techniques such as electron microscopy and photoelectron spectroscopy.

The chapter has also collaborated extensively with universities and corporations in Saudi Arabia, such as King Abdulaziz University (KAU), Effat University, and the Saudi Basic Industries Corporation (SABIC), to create events promoting materials science for undergraduates in Saudi Arabia. Additionally, the chapter introduced the "What is Materials Science?" program at KAUST, where undergraduate students from different universities in Saudi Arabia and organized locally and internationally.

high school students participating in summer research at KAUST are invited to learn more about materials science.

Through the KAUST-MRS Student Chapter, students participated online in the panel discussion of the MRS Sustainability Forum during the 2012 MRS Fall Meeting in Boston, Mass. The KAUST student chapter also organized a two-way live streaming of the virtual session "Career Paths in Materials Science" during the 2013 MRS Fall Meeting in Boston, at which the director of New Materials Solutions from SABIC Corporate Research and Innovation spoke from KAUST to an international audience.

Furthermore, the KAUST-MRS Chapter successfully developed a local version of the MRS Science as Art Competition, for which more than 50 submissions have been received over the past three years. Science as Art is one of the more wellattended events on the KAUST campus.

The members of the chapter also have been active in co-organizing international conferences at KAUST, such as the poster sessions of the MRS-endorsed meeting "The 1st International Workshop on Energy Storage" (2013), as well as "The International Colloquium on Flexible Electronics and Photovoltaics" (2015).

More recently, the MRS University Chapters Subcommittee developed an ongoing and sustainable program at MRS meetings that engages and empowers university chapters and features both onsite and virtual platforms. The goal is to enable students to create the program they desire on-site and to reach students who are unable to attend the meetings.

KAUST students Guy Olivier Ngongang Ndjawa, Ahmed Mansour, Rahim Munir, and Maha Alamoudi (under the supervision of Alshareef) responded to the call for proposals for student-organized events and submitted a proposal that was selected for the first student-led event on academic writing during the last MRS Fall Meeting. The team was motivated by the fact that success in academia is very much dependent on excellent writing.

Although this fact is well acknowledged in universities and colleges, the syllabi of many graduate programs across 
the world do not reflect this necessity. The students were determined to take advantage of the excellent platform offered by MRS to expose a large number of students to this set of writing skills that are critical for flourishing in academia and are transferable to many other sectors of life.

The event was structured as a threeday seminar series focused on writing skills required for a successful academic career. The seminars covered scientific writing, scientific papers and research proposals, and writing for professional orientation, academic resumes, cover letters, and CVs. All the sessions had a strong response of more than 80 attendees, ranging from doctoral students to laboratory principal investigators, with remarkable positive feedback from MRS headquarters, audience members, speakers, and sponsors of the event.

The event presentations were also recorded and will be broadcast online soon through MRS OnDemand ${ }^{\circledR}$ to reach audience members and students who were unable to attend the Meeting in Boston.

The key factor for the success of the event was the formation of a team of students passionate about academic writing who believe in the broad impact and its relevance for their peers and others outside their institution. Once the KAUST team was formed, they took advantage of networking opportunities to talk to various visiting professors and KAUST faculty members to shape the outline of the event. Long brainstorming sessions followed to define the program and to identify potential speakers and sponsors who shared the passion of the KAUST team, as well as their belief in the broad impact of the topic. The event was co-sponsored by the KAUST Solar Center, the university's Graduate Affairs Office, and various faculty members. In addition, MRS awarded the selected proposal.

The KAUST-MRS Chapter students overcame obstacles during this complex project through hard work and collaboration. The various tasks of arranging the logistics, finances, promotion, and connecting the parties involved were assigned to various members of the team based on his or her areas of expertise. MRS headquarters and the administration team at the KAUST Solar Center provided logistical support. The business managers at KAUST assisted in monitoring the funding and ensured that spending did not exceed the budget, while the team facilitated the transfer of funds between KAUST and MRS. Additionally, the

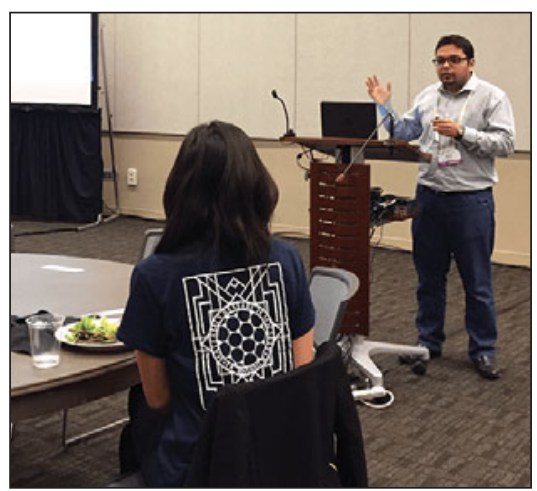

KAUST student Rahim Munir presents the KAUST-MRS Student Chapter's work to an audience of MRS Student Chapter members from universities around the world during the 2017 MRS Spring Meeting \& Exhibit. Photo by Caitlin Clark, KAUST News.

KAUST Marketing and Communications Department provided support by promoting the event in the university's media and through its social media presence. The student chapter team also took advantage of the visits from international professors, and used this opportunity to interview them on the topic of academic writing. The video interviews were posted online as promotional material for the event, and they are currently available on the YouTube channel ("Amelio-Smart").

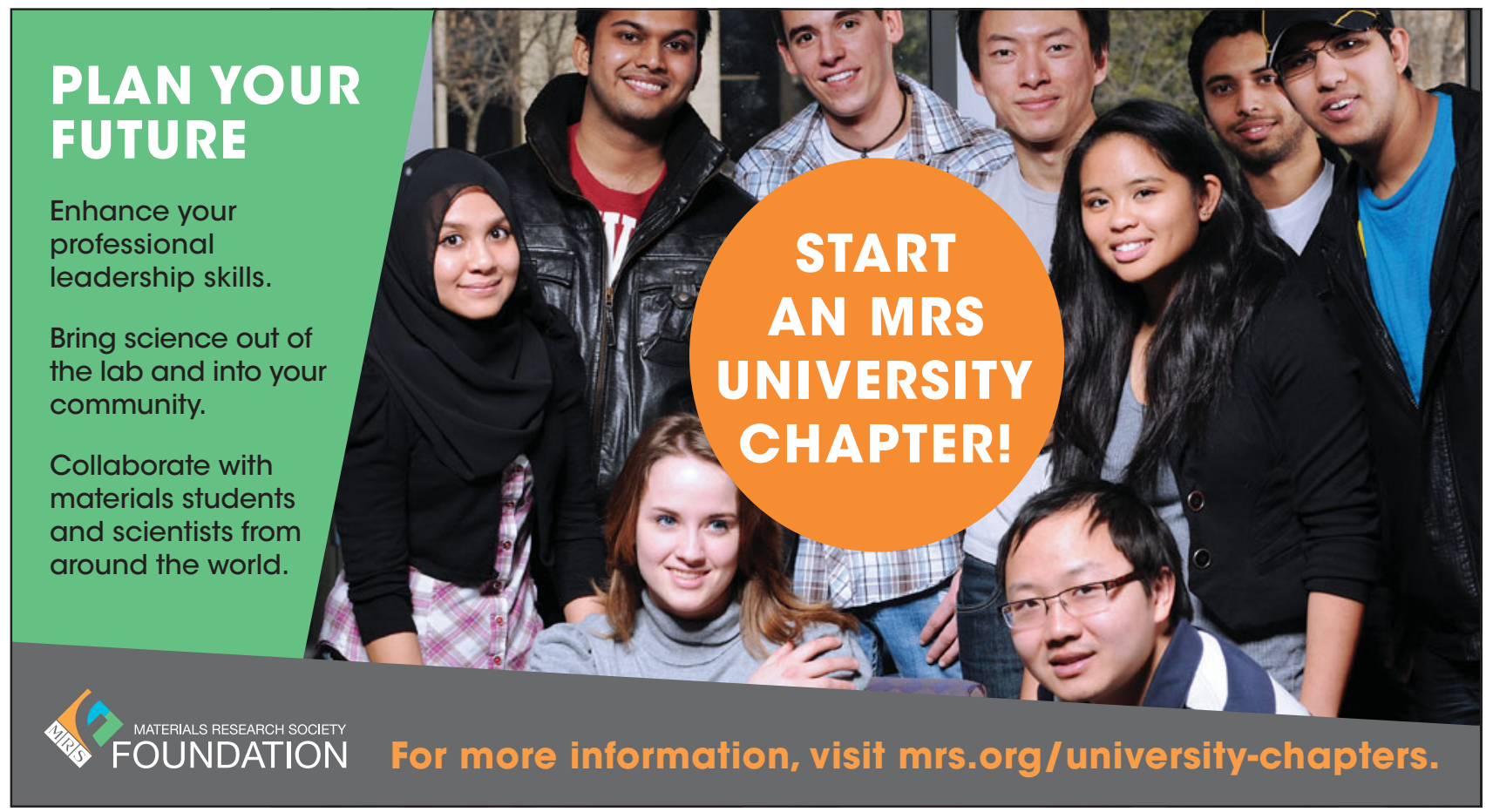

